\title{
As enfermeiras da força expedicionária brasileira no front italiano
}

\author{
THE BRAZILIAN EXPEDITIONARY FORCE'S NURSES IN THE ITALIAN FRONT \\ LAS ENFERMERAS DE LA FEB EN EL FRONT ITALIANO.
}

\author{
Margarida Maria Rocha Bernardes ${ }^{1}$, Gertrudes Teixeira Lopes²
}

\section{RESUMO}

Estudo histórico-social, analisa a proximidade das Enfermeiras do Exército na FEB junto às autoridades que detinham o poder dos comandos dos exércitos norte-americano e brasileiro durante a 2. ${ }^{\text {a }}$ Guerra. Fontes primárias: duas fotografias que se complementam e depoimentos de nove enfermeiras que estiveram no conflito. Fontes secundárias: acervo literário referente ao assunto. Alguns conceitos do sociólogo Pierre Bourdieu foram utilizados para apoiar a discussão. Resultados: as enfermeiras inseridas no meio militar tiveram tratamento diferenciado pelos Comandantes dos Exércitos Norte-Americano e Brasileiro, tendo maior visibilidade junto à tropa masculina e à mídia. As enfermeiras ganharam uma batalha, sendo respeitadas num mundo novo e desconhecido, no universo das Forças Armadas, historicamente dominado por homens. Integrando uma equipe, aquelas enfermeiras lutaram por autoafirmação e respeito naquele momento histórico peculiar.

\section{DESCRITORES}

História da enfermagem. Enfermagem militar. II Guerra Mundial.

\section{ABSTRACT}

This social-historical study analyzes the proximity between the nurses at the Brazilian Expeditionary Force (FEB, in the Portuguese-language acronym) and the authorities in charge of the U.S. the Brazilian Armies in World War II. Primary sources: two photographs that complement each other and reports from nine nurses who participated in the conflict. Secondary sources: literature on the subject. Some of Pierre Bourdieu's concepts were used to give support to the discussion. Conclusions: in the military milieu the nurses received a special treatment from the commanders of the U.S. and the Brazilian Armies, and had more visibility to the Brazilian nurses amongst soldiers and in the media. The nurses won a battle by being respected in a new and unknown world, within the universe of the Armed Forces, which is historically dominated by men. Working as part of a team, those nurses struggled for self-affirmation and respect in that peculiar historical moment.

\section{KEY WORDS}

History of nursing.

Military nursing.

World War II.

\section{RESUMEN}

Estudio histórico-social, analiza la proximidad de las enfermeras del Ejército en la FEB junto a las autoridades que detenían el comando de los Ejércitos Norte Americano y Brasileño durante la 2nda. Guerra Mundial. Fuente primaria: dos fotografías de la época que se complementan y las declaraciones de nueve enfermeras que estuvieron en el conflicto. Fuentes secundarias: el acervo literario referente al asunto. Utilizamos conceptos del sociólogo Pierre Bourdieu para apoyar la discusión. Los resultados evidenciaron que ellas tuvieron tratamiento diferenciado por los dos Ejércitos, cuyo objetivo era pasar mayor visibilidad a las brasileñas junto a la tropa masculina y también a la prensa. Evidenció la importancia que ese momento tuvo en sus vidas. Concluimos que ellas lucharon, imponiéndose en un mundo nuevo y desconocido, incluyéndose en un universo masculino militar. Integrando un equipo, lucharon para buscar auto-afirmación y respecto en aquél momento histórico peculiar.

\section{DESCRIPTORES}

Historia de la enfermería. Enfermería militar. Segunda Guerra Mundial.
1 Enfermeira. Bióloga Especialista em Administração em Serviços de Saúde. Mestre pela Faculdade de Enfermagem da Universidade do Estado do Rio de Janeiro (UERJ); Docente da Universidade Estácio de Sá. Enfermeira, supervisora do Hospital de Emergência Henrique Sérgio Gregori, em Resende. Rio de Janeiro, RJ, Brasil. margarbe@globo.com

2 Enfermeira. Livre Docente em Enfermagem. Professora Titular do Departamento de Fundamentos e Coordenadora do Programa de Mestrado da UERJ, Membro do Núcleo de História da Enfermagem Brasileira da Universidade Federal do Rio de Janeiro (Nuphebras/UFRJ) Pró-cientista da UERJ. Pesquisadora do CNPq. Rio de Janeiro, RJ, Brasil. gertrudes.lopes@ pesquisador.br gelopes@yahoo.com 


\section{APRESENTAÇÃO}

Em 1942, ao tornar-se um dos países aliados no conflito da $2^{\text {a }}$ Guerra Mundial, o Brasil criou uma força militar diferenciada e especial, a Força Expedicionária Brasileira (FEB). Na oportunidade, por imposição norte-americana, foram convocadas enfermeiras brasileiras voluntárias, com formação profissional diferenciada ${ }^{(1)}$.

Diversos e significativos foram os fatores que desencadearam este evento mundial. Um deles sem dúvida,tornou-se emblemático nesta guerra, merecendo destaque por ter sido considerado extremamente grave para o povo norte-americano que foi: [...] o ataque japonês a Pearl Harbor em 7 de dezembro de 1941, o que tornou a guerra mundial(2).

No Brasil, o momento político da Era Vargas (1930-1945) é o marco temporal onde aconteceram os fatos retratados nas fotos que apresentamos neste estudo.

O Brasil neutro durante o período inicial do conflito, sofre pressões internas e externas para se definir, decorrente de sua posição geográfica estratégica no cenário internacional e a condição política de ditadura. O afastamento entre o Brasil e a Alemanha, antes parceiros, tornou-se inevitável, seguindo-se uma aproximação com os Estados Unidos da América. Pela pressão popular nacional espontânea, o Brasil entra na $2^{\mathrm{a}}$ Guerra Mundial. As brasileiras profissionais de Enfermagem tiveram o privilégio deste pioneirismo, pois foi essa a profissão que se fez necessária para a mobilização do conflito.

A necessidade de criação de um Quadro de Enfermeiras para atuar no cenário da guerra, juntamente com o efetivo da FEB, se deu em função de uma solicitação dos aliados norteamericanos já que:

[...] as [enfermeiras] americanas já estavam sobrecarregadas de serviços, além do mais não falavam a língua dos futuros pacientes [brasileiros] [...] $]^{(3)}$.

Assim, houve o empenho do governo brasileiro de implementar em caráter de urgência a busca de voluntárias, de modo a atender a solicitação de um grupo hegemônico militar estrangeiro, [...] mandatários do Estado, detentores do monopólio de violência simbólica legítima[... $]^{(4)}$.

O jornal O Globo, de nove de outubro de 1943, publicou uma chamada solicitando mulheres entre dezoito até trinta e seis anos para aderirem ao voluntariado. Ao se apresentarem para seleção elas deveriam ser solteiras, viúvas ou separadas e comprovar alguma qualificação para o serviço de Enfermagem.

- Após a seleção, as enfermeiras, participaram em caráter obrigatório do Curso de Emergência de Enfermeiras da Re- serva do Exército (CEERE), ministrado pela Diretoria de Saúde do Exército, cujo objetivo era formar o Quadro de Enfermagem (QEERE) ${ }^{(5)}$. Este curso comportou três módulos distintos: parte teórica, preparação física e instrução militar ${ }^{(6)}$. Tal curso, possibilitou que as candidatas incorporassem o habitus militar, contribuindo para a padronização do comportamento dessas enfermeiras no Teatro de Operações (T.O.) na Itália.

Essa força de trabalho criada, organizada e preparada no Brasil, seguiu para a $2{ }^{\text {a }}$ Guerra Mundial, com o propósito de potencializar o recurso humano de Enfermagem dos países aliados, que atuava nos hospitais de campanha.

O conceito de força de trabalho remete a análise de aspectos gerais específicos da divisão de trabalho, da dinâmica de emprego e da qualificação técnica para o trabalho(7).

Neste contexto histórico marcante para a humanidade, as enfermeiras ousaram e entraram para o Exército Brasileiro, seguindo para o conflito mundial, inseridas na FEB, comandada pelo General João Batista Mascarenhas de Moraes ${ }^{(8)}$. Nesta Força foram para a Itália cento e oitenta e seis profissionais de saúde, entre eles, sessenta e sete enfermeiras do Exército, sendo sessenta e uma enfermeiras hospitalares e seis especializadas em transporte aéreo ${ }^{(9)}$.

Derivou-se como objetivo deste estudo é analisar a proximidade das enfermeiras do Exército na FEB com as autoridades que detinham o poder dos Comandos dos Exércitos Norte Americano e Brasileiro durante a $2^{\text {a }}$ Guerra Mundial.

Com a divulgação dessas fotografias (Figuras 1 e 2) e a discussão dos dados, este estudo pretende preencher, com imagens e relatos das participantes alguns lapsos da História da Enfermagem militar brasileira durante a $2^{\text {a }}$ Guerra Mundial, permitindo contribuir para que se ampliem conhecimentos para a prática da profissão, divulgando fontes primárias de dados, que se encontram arquivadas no Comando Militar do Leste (CML), no município do Rio de Janeiro. Assim, procuramos socializar com outros pesquisadores da História da Enfermagem a divulgação de fotografias do recorte temporal existente no referido arquivo.

\section{DESENHO DA PESQUISA}

Trata-se de um estudo histórico sociológico. Os dados primários preferenciais foram obtidos em dois documentos fotográficos que fazem parte do acervo iconográfico do Comando Militar do Leste (C.M.L.) e depoimentos orais de nove enfermeiras da FEB que atuaram na Itália, durante a $2^{\text {a }}$ Guerra.

As depoentes foram esclarecidas quanto aos objetivos da entrevista e concordaram em prestar seus depoimentos, permitindo suas identificações para o Centro de Memória 
Dra Nalva Pereira Caldas da Faculdade de Enfermagem da Universidade do Estado do Rio de Janeiro (FENF/UERJ), tornando possível sua utilização em pesquisas futuras. Os resultados dos depoimentos equiparam-se em importância às fotografias apresentadas. Em vista disso, o depoimento oral e as fotografias passaram a ser as fontes preferenciais do estudo.

Articulando depoimentos orais com as fotografias obtivemos dados inéditos não registrados em fontes oficiais. Esses procedimentos empregados na busca e análise das informações vislumbram uma nova maneira de revitalização da memória durante a entrevista e oferece uma inusitada possibilidade de pesquisa histórica.

Esta forma de articular os textos fotográficos com os depoimentos e os documentos, na pesquisa histórica, se apresenta como um método de investigação que possibilita ao pesquisador utilizar diferentes técnicas para aprofundar o conhecimento sobre um determinado fato em estudo. Denomina-se o método desenvolvido de Método Analítico Fotográfico Oral.

Ao realizarmos essa experiência, pretendíamos nos aproximar das experiências viven-ciadas pelas enfermeiras do Exército, durante a $2^{\circ}$ Guerra. Ao nos desafiarmos neste caminho metodológico, propomos uma nova maneira de pesquisar em história. Esperamos que este novo método possa contribuir no desvela-mento de fenômenos vinculados a essa área de conhecimento.

As fontes iconográficas e orais selecio-nadas foram submetidas à análise de conteúdo. Articular essas fontes favoreceu com maior profundidade a interpretação dos dados obtidos. Os dados que emergiram das fontes secundárias trataram do contexto histórico-social brasileiro dos anos quarenta, com destaque para o período da $2^{\text {a }}$ Guerra Mundial. Essas fontes foram coletadas em bibliografia da história do Brasil. Os conceitos de habitus e de campo do sociólogo francês Pierre Bourdieu, proporcionaram fundamentos para analisar os dados da pesquisa. A partir deles foi realizada a análise das relações dialéticas entre o habitus dos agentes e as estruturas do campo.

\section{AS ENFERMEIRAS DO EXÉRCITO E AS RELAÇÕES DE PODER ESTABELECIDAS}

O modelo social da década de quarenta se configurava como um mundo essencialmente masculino. A mulher estava inserida na sociedade totalmente voltada para o âmbito familiar. O caminho profissional feminino aceitável para as mulheres era o do magistério, principalmente o primário.

Neste cenário de um Brasil provinciano surgiu um grupamento de mulheres, fora do padrão delineado pela sociedade da época, com o ideal de seguir para a Guerra em defesa de seu país. Iniciava-se a formação de um grupamento feminino de Enfermagem que veio a compor os quadros do Exército Brasileiro, formado por mulheres que emergiram de um mundo familiar, protegido e limitado, e que se dispuseram a enfrentar um mundo heterogêneo em que vieram a conviver, lado a lado, com militares homens e outras mulheres, as enfermeiras norte-americanas, formadas em outro contexto. Elas estavam na Guerra há quatro anos, sendo detentoras de capital cultural institucionalizado e de habitus militar incorporado, conseqüentemente, adaptadas às rotinas hospitalares desenvolvidas no cenário de guerra, com maior poder de decisão e segurança do que as enfermeiras brasileiras que foram enfrentar um universo novo e desconhecido.

Nesse cenário de luta, tais enfermeiras participaram do contexto turbulento de uma Guerra Mundial, como enfermeiras de terceira classe do círculo de oficiais subalternos do Exército Brasileiro, (posto criado exclusivamente para elas, não existindo na hierarquia militar) em desigualdade com as enfermeiras brasileiras, formadas pela Escola de Enfermagem Anna Nery, com posto hierárquico de tenentes da Força Aérea Brasileira (FAB), no contingente da FEB e as enfermeiras norte-americanas que ocupavam diversos postos hierárquicos, com situação definida de soldo e graduações militares. Associada as situações anteriores, ainda se viram diante de barreira lingüística e de um clima adverso como o da Europa. Passaram a integrar uma equipe multiprofissional composta por brasileiros e estrangeiros, grupos com formações técnicas e culturais diversificadas. Neste mundo militar, com disciplina rígida, as mulheres tiveram que lutar para buscar auto- afirmação e respeito da comunidade militar da qual participavam.

Durante esse estudo foi possível refletir o passado, no momento presente, por meio de leituras fotográficas daquele período histórico que as depoentes viveram, relembradas por elas através dos seus depoimentos orais. Desta forma, podemos perceber que a oposição passado/presente é essencial na aquisição da consciência do tempo [... $]^{(10)}$.

Portanto, entendemos que a luta das enfermeiras brasileiras pela inserção na FEB aconteceu durante todo o processo de incorporação e permanência das mesmas, demandando esforços para adaptação ao novo mundo, luta enfrentada com coragem e determinação.

Nesta linha de pensamento, os participantes de movimentos sociais, por mais diversas que sejam suas origens, objetivos ou projetos pessoais, adquirem um conjunto de traços comuns que lhes dão aparência de família, com reações similares ${ }^{(11)}$.

Assim, as enfermeiras, ao viverem a experiência de participação numa Grande Guerra Mundial, foram marcadas e diferenciaram-se das outras moças da época, mantendo elos de relações e aproximando-as durante toda a vida. 
O Exército Brasileiro sem grupamento feminino, teve que rapidamente organizar-se para atender à solicitação norteamericana, concedendo as nossas enfermeiras espaço social para cuidar dos feridos. Assim, podemos deduzir que o ingresso das enfermeiras no Teatro de Operações (T.O.) representou uma estratégia de condescendência, através dos quais os agentes que ocupavam uma posição militar hierárquica superior demonstraram apoio a um outro grupo, as enfermeiras do Exército incorporadas ao contingente da FEB, inserindo-as no cenário da guerra, assegurando o reconhecimento da distância social, pela denegação simbólica da distância.

As estratégias de condescendência se configuram como o melhor exemplo para mostrar que a preocupação de voltar às coisas tais como elas são e de chegar mais perto da realidade[...]...consiste em tirar proveito da relação de forças $[\ldots]^{(12)}$.

Já no T.O., as enfermeiras ocuparam os espaços sociais consentidos, mantendo-os durante o transcorrer da Guerra. Nas duas fotografias a seguir analisadas, pode-se ver que as enfermeiras brasileiras ocuparam um lugar de destaque na ocasião, sendo prestigiadas perante o contingente brasileiro que estava em ação. Tal oportunidade deu-lhes visibilidade e, inquestionavelmente, contribuiu para demarcar frente aos homens, a participação das mulheres brasileiras na $2^{\mathrm{a}}$ Guerra. Com sua atuação abriram, sem dúvida, um caminho profissional e contribuíram para divulgar a Enfermagem.

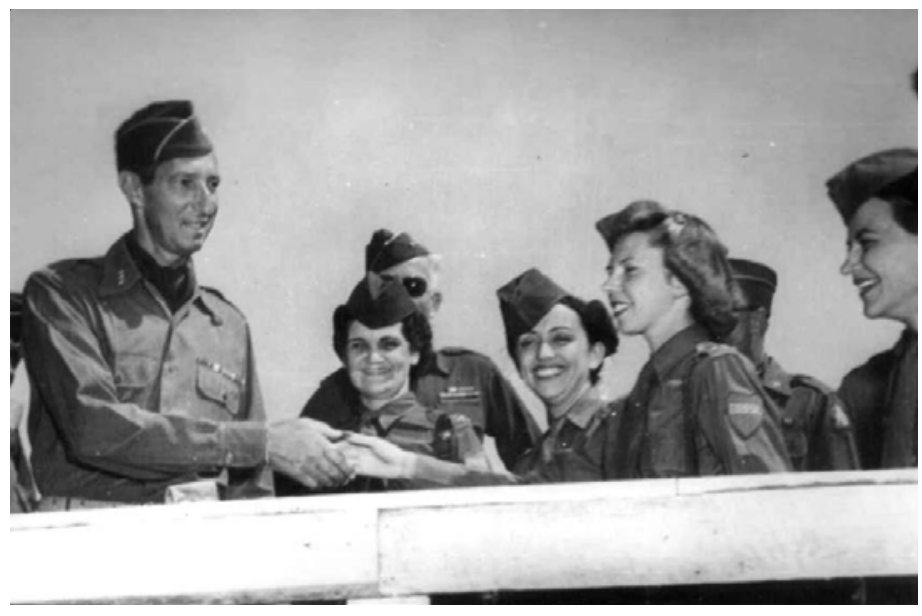

Figura 1 - Cumprimento do General Mark Wine Clark, Comandante do V Exército Norte-Americano que incorporou a tropa brasileira no Teatro de Operações na Itália. Localização: $5^{a}$ Seção do C.M.L., Subseção de Áudio- Visuais

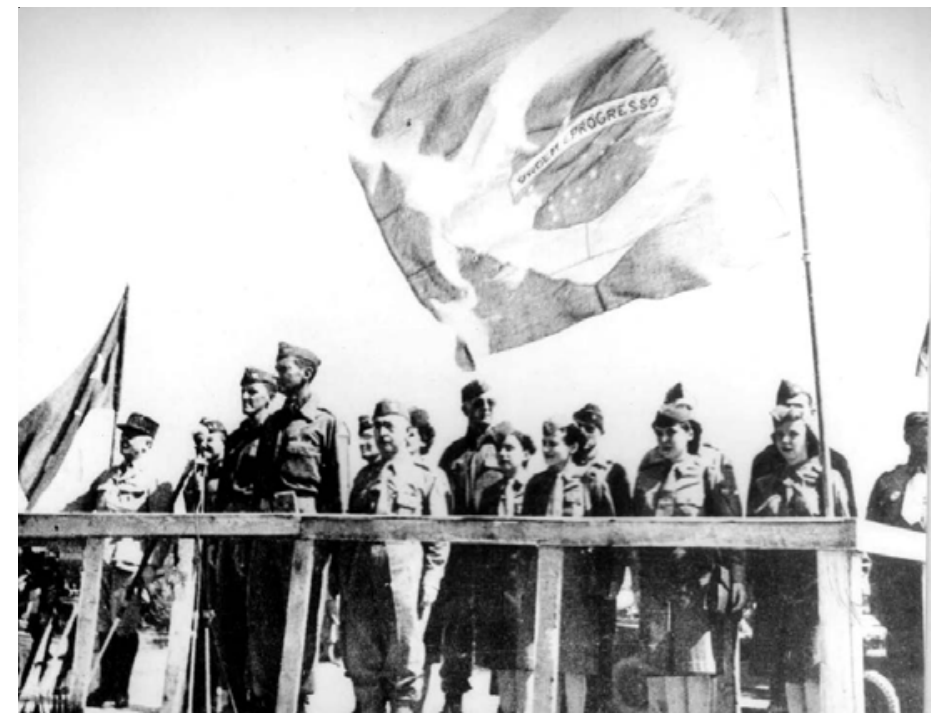

Figura 2 - Apresentação oficial da tropa brasileira pelo seu Comandante, General Mascarenhas de Moraes ao Comandante do V Exército Norte-Americano, General Mark Wine Clark, tendo no palanque a presença em destaque das enfermeiras do Exército Brasileiro. Localização: $5^{a}$ Seção do C.M.L., Subseção de Áudio-Visuais e, coleção particular da agente do estudo Virgínia Maria de Niemeyer Portocarrero 
As duas fotografias têm muitas semelhanças. Ao escolhermos a Figura 1 e levarmos para a primeira entrevista tentativa que fizemos ao iniciar a pesquisa, a enfermeira entrevistada trouxe-nos outra fotografia (Figura 2) de seu diário pessoal, que contemplava diferentes detalhes daquele evento. $\mathrm{O}$ depoimento oral articulado à fotografia não somente serviu para ler a foto, mas para aguçar as lembranças e fazer nexos e conexões importantes sobre o momento referido na mesma.

Recortamos os seguintes relatos sobre a Figura 1, que subsidiaram a análise fotográfica:

[...] aqui é uma foto histórica[...] foi o dia em que a FEB foi apresentada e entregue ao $\mathrm{V}$ Exército Americano [...] aqui está o General Mark Clark, General Mascarenhas, Major Walters, ajudante de ordens do General Mark Clark[...] ele falava muito bem português[...]as colegas[...]Olga Mendes, Carmem Bebiano, eu e a Virgínia [...] nós fomos apresentadas e passamos a fazer parte do $\mathrm{V}$ Exército Americano[...] (Enfermeira Bertha Moraes).

A enfermeira ainda informa:

[...]General Mark Clark cumprimentando a Virgínia[...] podese ver a Olga, a Antonieta, Carmem e Bertha[...]as cinco [ presentes na foto] representaram as enfermeiras nesse vinte e cinco de agosto[de 1943] [...] (Enfermeira Elza Cansanção).

A fala que se segue é esclarecedora:

[...] foi em Tarqüinia, quando o Exército Brasileiro foi recebido no $\vee$ Exército Americano pelo General Mark Clark[...] (Enfermeira Virgínia Portocarrero).

A Figura 1 registra o cumprimento entre o General Mark Clark e a enfermeira Virgínia. Todos os presentes na composição estão sorridentes. Da esquerda para a direita vê-se a figura semi encoberta de um militar não identificado, em seguida o General Mark Clark, que foi reconhecido por todas as depoentes como sendo o Comandante do V Exército Norte-Americano. Na mesma ordem, também reconhecidas por todas, temos as enfermeiras Olga Mendes, Antonieta Ferreira, Virgínia Portocarrero, Carmem Bebiano e Bertha Moraes. O momento é eloqüente a ponto de fazer todos sorrirem. Para elas essa foto tem um significado de poder e prestígio, já que lhes coube lugar de destaque ladeando personalidades importantes e hierarquicamente detentoras de alto posto militar.

O depoimento da enfermeira Bertha Moraes sobre a cerimônia onde diz que a FEB foi [...] apresentada e entregue ao $V$ Exército Americano [...], demarca e fica subtendido o ato de heroísmo dos militares combatentes que se apresentaram cumprindo determinações norte-americanas, prontos para entrar em combate naquele conflito mundial. Entendemos que as imagens contam a história.

A Figura 2, foi publicada em livro(3), onde confere-se a identificação das pessoas da esquerda para à direita como sendo os Generais Mark Clark, Mascarenhas de Moraes, o Major americano Vernon Walters, e as tenentes enfermeiras anteriormente citadas.

A fotografia parece chamá-los para que se posicionem de forma a mostrar sua melhor imagem, perpetuando uma técnica que atestou a importância desse cumprimento para aquela comunidade. Temos como hipótese provável, não confirmada por nenhuma das depoentes que a escolha do fotógrafo em perpetuar o cumprimento do reconhecido e importante General àquela enfermeira, pode estar associada à descendência militar da mesma e a coincidência de estar na guerra, junto com mais quatro jovens primos irmãos. Isto se traduz na afirmativa:

\section{[...] eu pertenço a duas famílias de militares, por parte de mãe, minha mãe era neta de Marechal, esteve na Guerra do Paraguai e, por parte de pai, o General Hermenegildo Portocarrero[...][para a guerra][...]fomos quatro primos ir- mãos, que nós chamamos até de irmãos primos[...]porque o fotógrafo provavelmente me escolheu ?[...]isso aí não foi escolha[...]cada uma ia se apresentando e quando eu o cumprimentei bateram a foto[...]a sorte foi minha[...] (En- fermeira Virgínia Portocarrero).}

Acreditamos que uma família brasileira ao mandar quatro jovens membros para a guerra, correndo perigo eminente $\mathrm{e}$ real de vida, gera um fato, merece uma foto, o que não passou desapercebido para o fotógrafo, repórter de guerra.

A Figura 2 é um retrato rico em símbolos de autoridade e hierarquia. Observando atentamente os retratados, percebemos que as figuras masculinas estão posicionadas à frente das mulheres no palanque. O posicionamento à frente das mulheres reforça a noção de hierarquia e disciplina, destacando a diferença entre as patentes dos fotografados, demarcando com seus corpos a posição social. A atenção do fotógrafo nitidamente centrou-se nas figuras femininas, apesar da indumentária dos homens mostrar mais símbolos e divisas, significando que eles detinham maior poder.

Recortamos as falas que confirmam a leitura fotográfica da Figura 2:

[...] [as enfermeiras] foram chamadas ao palanque, quando a tropa desfilou perante o General Mark Clark[...]tem também o General Mascarenhas [...]você olhava para ele era uma criatura de uma força tremenda, sisudo e sério, mas quando a gente se aproximava era um pai[...] (Enfermeira Isabel Feitosa).

O depoimento a seguir é esclarecedor:

[...] a disposição espacial dos militares [...] o General tem que estar à frente [...] as autoridades sempre à frente[...] a mais alta patente vem à frente e vai em ordem decrescente [...] para ele [Mark Clark] [...] foi uma honra comandar os brasileiros[...] [ele] elogiou todo nosso trabalho[...]nossa bravura[...]é uma coisa que cala no coração da gente[...] (Enfermeira Elza Cansanção). 
A coincidência do local realça a importância que o fato teve também para o fotógrafo. As imagens mostram um espaço físico e os fotografados envolvidos num mesmo processo. Este conhecimento estático que a fotografia oferece numa observação direta.

Assim, as enfermeiras, estando presentes e se deixando fotografar, acabaram participando da solenidade sem se preocupar em saber se poderiam dizer alguma coisa, revelando muito claramente que não estavam ali para dizer algo, mas por razões bem outras, sobretudo para verem e serem vistas $^{(13)}$.

Trata-se de um conjunto de pessoas, no espaço físico da Itália, com o intuito de instituir uma nacionalidade à participação brasileira no conflito, comemorando uma data representativa para o nosso Exército. A presença do Chefe do V Exército Norte-Americano, General Mark Clark nessa comemoração cívica veio demonstrar o apreço do mesmo à corporação que se aliou, prestigiando nosso sentimento de nacionalidade. Essas fotografias têm o claro sentido de divulgar a consideração dispensada.

Visto dessa maneira, utilizamos a seguinte reflexão teórica que contribui para complementação do acima referido:

\begin{abstract}
A investidura[...]consiste em sancionar e em santificar uma diferença (préexistente ou não), fazendo-a conhecer e reconhecer, fazendo-a existir enquanto diferença social, conhecida e reconhecida pelo agente investido e pelos demais $[\ldots]^{(14)}$.
\end{abstract}

O General Mark Clark ao comparecer a esta comemoração, não deixa de situar-se e distinguir-se, tentando negar a distância entre os dois países aliados, o que ratifica a distância diferencial constitutiva de sua posição. Nesta oportunidade, novamente aparecem as estratégias de condescendência que são muito utilizadas pelos $\operatorname{poderosos}^{(13)}$.

As imagens das duas fotografias documentam a passagem da descontração reservada da primeira, para a atenção apresentada na segunda, mostrando nessa última foto o respeito de todos ao objeto de seus olhares: a tropa brasileira que desfilava. O depoimento confere credibilidade ao que referimos:

[ foi ] [...] dia de muita emoção para nós, só vendo aquela massa verde de uniformes brasileiros perto[...] o desfile do verde oliva me emocionou demais [...] o mastro da bandeira achava-se bem na minha frente[...] (Enfermeira Virgínia Potocarrero).

Na Figura 2 pode ser observada a transformação marcante dos fotografados, em um novo espaço físico. Os militares posicionam seus corpos de acordo com os habitus adquiridos ao longo de sua trajetória profissional e perfilam-se com atenção e olhares direcionados para o mesmo ponto. Nessa foto a bandeira brasileira, símbolo da nossa nacionalidade tremula sobre a cabeça das autoridades.

Analisados com o olhar atento, os dois retratos sendo mostram a proximidade das enfermeiras com o poder hierárquico militar do Brasil e dos Estados Unidos da América. As fotos na realidade retratam o poder militar vigente no T.O. As enfermeiras foram convidadas para compor o palanque, sendo fotografadas uniformizadas e em posição de sentido, ao lado dos militares, resultando num ganho simbólico que foi a saudação da tropa brasileira ao lado das autoridades militares mais importantes do conflito. $\mathrm{O}$ ar solene das pessoas na Figura 2 dá o caráter cerimonial do evento.

\section{CONSIDERAÇÕES FINAIS}

A participação de mulheres enfermeiras no Exército Brasileiro foi viabilizada pela necessidade da FEB de possuir em seus quadros um Grupamento Feminino de Enfermagem, imposto pelo V Exército Norte-Americano. Em razão disso, mulheres brasileiras foram selecionadas e rapidamente preparadas para enfrentarem a guerra, num país distante.

Inseridas no Quadro de Enfermeiras de Emergência da Reserva do Exército, como enfermeiras de $3^{\circ}$ classe do Círculo de Oficiais Subalternos. Foram arvoradas $^{(a)}$ tenentes enfermeiras, no T.O. pelo General Mascarenhas de Moraes, comandante da FEB. Dessa maneira tiveram sua situação profissional e militar regularizadas, portanto, reconhecidas legalmente no Exército Brasileiro.

A determinação do governo norte-americano correspondeu à imposição de uma visão de mundo hegemônica, constituindo-se em violência simbólica, permitindo porém, a inserção da mulher enfermeira no campo militar, contribuindo para a valorização da mulher na sociedade brasileira. Estas enfermeiras praticaram um ato ousado para a sociedade brasileira da época, já que a aceitação desse grupamento, num ambiente masculino foi vista com resistência e crítica pela sociedade. Assim, elas abrem um espaço no campo profissional para a mulher brasileira.

Pelo que representa para nossa profissão a trajetória dessas enfermeiras concluímos que sua luta, foi um marco na inserção das mulheres nas Forças Armadas do Brasil, pois provam a possibilidade da mulher ser militar e desempenhar as funções que lhes foram atribuídas. As guerras possuem uma face cruel e desumana, trazendo inegavelmente avanços tecnológicos, porém, cabe à Enfermagem um papel humano nos conflitos.

(a) Este posto militar foi criado exclusivamente para elas, não existindo atualmente na hierarquia militar.Fonte: Diário pessoal da enfermeira Virgínia Maria de Niemeyer Portocarrero 
1. Castello BM. O Brasil na $2^{\mathrm{a}}$ Guerra Mundial. Rio de Janeiro: Bibliex; 1960.

2. Hobsbawm E. Era dos extremos: o breve século XX: 1942-1999. São Paulo: Companhia das Letras; 1999.

3. Medeiros EC. Eu estava lá! Rio de Janeiro: Ágora da Ilha; 2001.

4. Bourdieu P. O poder simbólico. Rio de Janeiro: Bertrand Brasil; 1998.

5. Mulher brasileira enfermeiras da FEB. Revista Verde-Oliva. 1995;23(144):91-2. [edição histórica].

6. Silveira JX. A FEB por um soldado. Rio de Janeiro: Expressão e Cultura; 2000.

7. Costa e Silva, LIM, Peduzzi M. Os recursos humanos de enfermagem da perspectiva da força de trabalho: análise da produção científica. Rev Esc Enferm USP. 2005;39(n. esp): 589-96.
8. Medeiros EC. 1...2...Esquerda...Direita!...Acertem o passo. Maceió: Cian Gráfica e Ed.; 2003.

9. Motta AM, coordenador. História oral do Exército na Segunda Guerra Mundial. Rio de Janeiro: Biblioteca do Exército; 2001.

10. Le Goff J. História e memória. Campinas: Unicamp; 1992.

11. Bourdieu P. Contrafogos 2 : por um movimento social europeu. Rio de Janeiro: Jorge Zahar; 2001.

12. Bourdieu P. A economia das trocas lingüísticas: o que falar quer dizer. São Paulo: Ed. USP; 1998.

13. Bourdieu P. Sobre a televisão. Rio de Janeiro: Jorge Zahar; 1997.

14. Bourdieu P. Razões práticas sobre a teoria da ação. Campinas: Papirus; 1997. 